студентов с международным участием «Актуальные вопросы современной медицины» (81-ой итоговой научно-практической кон-ференции НОМУС им. И. И. Мечникова ИГМУ), Иркутск, 2014 - С. 96

4. Болезни полости рта / под ред. Л.М. Лукиных. - Н. Новгород: Изд-во НижГМА, 2014. - 508 с.

5. Гажва, С.И. Сравнительный анализ уровня стоматологического здо-ровья детского населения в регионах с различным содержанием фто-ридов в питьевой воде [Электронный ресурс] / С.И. Гажва, М. В. Га-даева // Современные проблемы науки и образования. - 2014. - №6. - Режим доступа: www.science-education.ru/12015734

6. Гажва, С.И. Этиопатогенетические механизмы развития флюороза зубов / С.И. Гажва, М.В. Гадаева // Фундаментальные исследования 2014. - №7. - С. 181-186.

\title{
Китаева P.P. \\ Использование диодного лазера в комплексном лечении тканей пародонта
} ФГБОУ ВПО «Пензенский государственный университет» doi: 10.18411/trnio-10-2021-96

(Россия, Пенза)

\section{Аннотация}

Пародонтит является актуальной проблемой в современной стоматологии, представляя хроническое воспалительное заболевание многофакторной этиологии. Одной из наиболее часто регистрируемых причин данной патологии является формирование бактериальной пленки, которая усугубляет течение воспалительного процесса. Основными этапами данного патологического процесса являются: местно-специфическая деградация поддерживающей ткани зуба, образование пародонтального кармана, рецессия десен и потеря зуба. Изменение зубного ряда при потере зуба оказывает значительное влияние не только на физиологические аспекты зубочелюстного аппарата, но и затрагивает эстетические вопросы, влияя на качество жизни пациентов.

В связи с этим поиск новых методик лечения пародонтита является перспективным направлением в современной стоматологической практике. Отмечено, что лазерная терапия получила широкое распространение как лечебная методика при заболеваниях пародонта. Диодный лазер на данный момент времени является самым популярным в стоматологии, преимуществом которого является небольшая стоимость, компактность и простота в применении.

Основными положительными эффектами данного лазера являются следующие: антибактериальный (снижение степени обсемененности пародонтогенными микроорганизмами), противовоспалительный (уменьшение выработки провоспалительных цитокинов), биостимулирующий (активация синтеза коллагена, выработка фибриногена и др.). Ряд данных, полученных в результате исследований, свидетельствует об эффективности применения диодного лазера при лечении заболеваний тканей пародонта.

Таким образом, его использование может быть рассмотрено как альтернатива традиционным механическим способам, связанным с применением химических агентов антисептического действия, так и составляющая часть комплексного лечения при среднетяжелом и тяжелом течении патологического процесса.

Ключевые слова: пародонтит, диодный лазер, пародонтальный карман, микроорганизмы, фибробласты, коллаген.

\section{Abstract}

Periodontitis is an urgent problem in modern dentistry, representing a chronic inflammatory disease of multifactorial etiology. One of the most frequently recorded causes of this pathology is the formation of a bacterial film, which aggravates the course of the inflammatory process. The main stages of this pathological process are: local-specific degradation of the supporting tooth tissue, the formation of a periodontal pocket, gum recession and tooth loss. Changes in the dentition with the loss of a tooth has a significant impact not only on the physiological aspects of the dentoalveolar apparatus, but also affects aesthetic issues, affecting the quality of life of patients. 
In this regard, the search for new methods of treating periodontitis is a promising direction in modern dental practice. It is noted that laser therapy has become widespread as a therapeutic technique for periodontal diseases. Diode laser is currently the most popular in dentistry, the advantage of which is low cost, compactness and ease of use.

The main positive effects of this laser are the following: antibacterial (decrease in the degree of contamination by periodontal microorganisms), anti-inflammatory (decrease in the production of pro-inflammatory cytokines), biostimulating (activation of collagen synthesis, production of fibrinogen, etc.). A number of data obtained as a result of research indicates the effectiveness of the use of a diode laser in the treatment of periodontal tissue diseases.

Thus, its use can be considered as an alternative to traditional mechanical methods associated with the use of chemical agents of antiseptic action, and as a component of complex treatment for moderate and severe course of the pathological process. collagen.

Keywords: periodontitis, diode laser, periodontal pocket, microorganisms, fibroblasts,

\section{Введение.}

Заболевания тканей пародонта относятся к группе многофакторной патологии, которой страдает большинство населения во всем мире.

Данная патология характеризуется разрушением тканей и высокой частотой прогрессирования вследствие сложных взаимодействий между микроорганизмами, факторами окружающей среды и тканями хозяина $[1,2]$.

Заболеваниям тканей пародонта подвержено $81 \%$ взрослого населения страны старше 35 лет. Совершенствование методов профилактики и лечения заболеваний пародонта, прогрессирующих с возрастом, составляет одну из наиболее важных проблем стоматологии [1]. Применение диодного лазера в стоматологии открывает новые возможности в качестве и сроках проводимого лечения.

Цель работы: анализ литературных данных, посвященный вопросу использования диодного лазера в комплексном лечении тканей пародонта.

Широкая распространенность патологии пародонта среди населения и отсутствие единого взгляда на восстановление зубочелюстной системы определяют не только медицинскую, но и социальную значимость проблемы реабилитации данной когорты пациентов. Исследования указывают на роль пародонтопатогенных бактерий в увеличении риска развития заболеваний сердца, диабета, респираторных инфекций и др. [3].

Лазерные технологии доказали прямое разрушающее действие на бактерии. Их принцип действия основан на передаче энергии тканям, которая затем преобразуется в тепло и, следовательно, увеличивает температуру ткани [4].

Диодный лазер - это полупроводниковый лазер, который обычно включает комбинацию галлия (Ga), арсенида (As) и других элементов, таких как алюминий (Al) и индий (In), для преобразования электрической энергии в энергию света. Рабочие длины волн диодных лазеров (помимо теплопередачи) не взаимодействуют с минерализованными тканями, что позволяет безопасно использовать их для проведения следующих процедур: санации борозды, абляции мягких тканей, гемостаза в пародонтальных карманах даже в непосредственной близости от корней зубов [6]. Преимущества данных лазеров включают чрезвычайную компактность, доступность, простоту эксплуатации, простую настройку и универсальность.

В литературе имеется достаточное количество опубликованных работ, посвященных применению диодных лазеров в лечении хронического пародонтита, однако их результаты демонстрируют значительную неоднородность в полученных результатах вследствие разного дизайна исследований. Кроме того, сложность сравнительной оценки результатов связана с неоднородностью используемых длин лазерных волн и клинических параметров, оцениваемых после проведенного лечения [7, 8, 9]. 
Метаанализ, проведенный Jia et al, 2020, оценил положительное влияние диодного лазера в качестве монотерапии и дополнения к лечению патологии пародонта [10]. Gutknecht et al. [11] и Garcez et al. [12] было продемонстрировано, что использование лазерного диодного излучения в инфицированных корневых каналах значительно снижает обсемененность микробами $[11,12]$. Кроме того, было отмечено, что лазеры обладают свойствами биостимуляции: увеличивают выработку коллагена, повышают активность ферментов, микро- и лимфообращение, а также пролиферацию фибробластов и остеобластов $[13,14]$.

Большинством авторов был сделан вывод, что фототермические свойства фотонной энергии диодного лазера способствуют развитию следующих положительных эффектов [15, $16]$.

1. Снижению степени бактериальной обсемененности Aggregatibacter actinomycetemcomitans и Porphyromonas gingivalis.

2. У Уеньшению выраженности воспалительных явлений (снижение количества провоспалительных цитокинов, улучшение лимфатической циркуляции и т.д.).

3. Квазифотобиомодуляции, проявляющейся уменьшением болевых ощущений.

4. Биостимуляции, проявляющейся увеличением крово- и лимфообращения, активацией синтеза коллагена, пролифераций фибробластов и остеобластов.

Многими авторами отмечено, что лазерное лечение с применением диодного лазера было предложено в качестве возможной терапевтической альтернативы традиционным механическим способом, связанным с использованием химических агентов с антисептическим действием или в сочетании с традиционной терапией $[17,18]$.

Вывод. Лечение заболеваний пародонта с использованием диодных лазеров обеспечивает бактерицидный эффект, снижение воспалительной реакции и поддерживает процесс заживления в зубодесневых карманах. Лазерная фотобиостимуляция активирует местный кровоток и стимулирует рост эндотелиоцитов. Преимущества лазерных технологий и тенденция к прогрессированию заболеваний пародонта позволяют активно включать стоматологические лазеры в комплекс мероприятий по лечению воспалительных процессов десны.

$$
* * *
$$

1. Cheng Y, Chen JW, Ge MK, Zhou ZY, Yin X, Zou SJ. Efficacy of adjunctive laser in non-surgical periodontal treatment: A systematic review and meta-analysis. Lasers in Medical Science. 2016; 31: 151-163. https://doi.org/10.1007/s10103-015-1795-5 (2016).

2. Mulder-van Staden S, Holmes H, Hille J. In vivo investigation of diode laser application on red complex bacteria in non-surgical periodontal therapy: a split-mouth randomised control trial. Sci Rep. 2020; 10: 21311. https://doi.org/10.1038/s41598-020-78435-7

3. Bartold PM, Van Dyke TE. An appraisal of the role of specific bacteria in the initial pathogenesis of periodontitis. $\mathrm{J}$ Clin Periodontol. 2019; 46(1): 6-11. doi: 10.1111/jcpe.13046 PMCID: PMC6357965

4. Giannelli M, Lasagni M, Bani D. Photonic therapy in periodontal diseases an overview with appraisal of the literature and reasoned treatment recommendations. Int. J. Mol. Sci. 2019; 20: 4741. https://doi.org/10.3390/ijms20194741.

5. $\quad$ Blayden, J, Mott A. Soft-Tissue Lasers in Dental Hygiene. Wiley-Blackwell; 2012:1-229.

6. Sumra N, Kulshrestha R, Umale V, Chandurkar K. Lasers in non-surgical periodontal treatment. J. Cosmet. Laser Ther. 2019; 21: 255-261. https://doi.org/10.1080/14764172.2018.1525744.

7. Alves VTE, Andrade AKP, Toaliar JM, Conde MC, Zezell DM, Cai S, et al. Clinical and microbiological evaluation of high intensity diode laser adjutant to non-surgical periodontal treatment: A 6-month clinical trial. Clin. Oral Investig. 2013; 17: 87-95. https://doi.org/10.1007/s00784-012-0703-7.

8. Cappuyns I, Cionca N, Wick P, Giannopoulou C, Mombelli A. Treatment of residual pockets with photodynamic therapy, diode laser, or deep scaling. A randomized, split-mouth controlled clinical trial. Lasers Med. Sci. 2012; 27: 979-986. https://doi.org/10.1007/s10103-011-1027-6. 
9. Balata ML, Andrade LP, Santos DBN, Cavalcanti AL, Tunes UR, Ribeiro EDP, et al. Photodynamic therapy associated with full-mouth ultrasonic debridement in the treatment of severe chronic periodontitis: A randomizedcontrolled clinical trial. J. Appl. Oral Sci. 2013; 21: 208-214. https://doi.org/10.1590/1678-7757201302366.

10. Jia L, Jia J, Xie M, Zhang X, Li T, Shi L, et al. Clinical attachment level gain of lasers in scaling and root planing of chronic periodontitis: a network meta-analysis of randomized controlled clinical trials. Lasers Med Sci. 2020; 35(2): 473-485. doi:10.1007/s10103-019-02875-5

11. Gutknecht N, Franzen R, Schippers M. Bactericidal effect of a 980-nm diode laser in the root canal wall dentin of bovine teeth. J Clin Laser Med Surg. 2004; 22: 9-13.

12. Silva Garcez A, Núñez SC, Lage-Marques JL. Efficiency of $\mathrm{NaOCl}$ and laser-assisted photosensitization on the reduction of Enterococcus faecalis in vitro. Oral Surg Oral Med Oral Pathol Oral Radiol Endod. 2006; 102(4): e93-8. DOI:10.1016/j.tripleo.2006.02.015

13. Ren C, McGrath C, Jin L, Zhang C, Yang Y. Effect of diode low-level lasers on fibroblasts derived from human periodontal tissue: a systematic review of in vitro studies. Lasers Med Sci. 2016; 31(7): 1493-1510. doi:10.1007/s10103-016-2026-4

14. Huertas RM, De Luna-Bertos E, Ramos-Torrecillas J, Leyva FM, Ruiz C, García-Martínez O. Effect and clinical implications of the low-energy diode laser on bone cell proliferation. Biol Res Nurs. 2014; 16(2): 191-196. doi:10.1177/1099800413482695

15. Mikami R, Mizutani K, Sasaki Y, Iwata T, Aoki A. Patient-reported outcomes of laser- assisted pain control following non-surgical and surgical periodontal therapy: a systematic review and meta-analysis. PLoS One. 2020; 15(9): e0238659. doi:10.1371/journal.pone.0238659

16. Majumder P, Ghosh S, Dey SK. Matrix metalloproteinase gene polymorphisms in chronic periodontitis: a casecontrol study in the Indian population. J Genet. 2019; 98: 32. doi:10.1007/s12041-019-1077-2

17. Malchiodi L, Caricasulo R, Cucchi A, Vinci R, Agliardi E, Gherlone E. Evaluation of Ultrashort and Longer Implants with Microrough Surfaces: Results of a 24- to 36-Month Prospective Study. Int. J. Oral Maxillofac. Implants. 2017; 32: 171-179.

18. Vinci R, Teté G, Lucchetti F.R, Capparé P, Gherlone EF. Implant survival rate in calvarial bone grafts: A retrospective clinical study with 10 year follow-up. Clin. Implant. Dent. Relat. Res. 2019; 21: 662-668.

\section{Курмангалиева С.С., Ажмуратова М.А., Мусабаева С.Ж., Мурат А.Т. Научно-исследовательское обоснование эффективности симуляционного курса у студентов медиков}

НАО «Западно-Казахстанский медицинский университет имени Марата Оспанова» (Казахстан, Актобе)

doi: 10.18411/trnio-10-2021-97

\section{Аннотация}

В статье рассматриваются вопросы разработки симуляционных тренингов и курсов. Представлен опыт ЗКМУ имени Марата Оспанова по анализу и разработке симуляционных курсов дисциплин в рамках научного проекта. Представлены некоторые этапы разработки, анализ их эффективности, обоснована необходимость разработки целостной модели симуляционного обучения в рамках образовательной программы.

Ключевые слова: медицинское образование, симуляционное обучение, практикоориентированное обучение.

\section{Abstract}

The article deals with the development of simulation training and courses. The experience of ZKMU named after Marat Ospanov in the analysis and development of medical simulation courses within the framework of a scientific project is presented. Some stages of development and analysis of their effectiveness are presented, the need to develop a holistic model of simulation training within the educational program is substantiated.

Keywords: medical education, simulation training, practice-oriented training.

\section{Введение.}

Согласно Стратегии развития медицинского образования в РК, перед ВУЗами поставлена задача обеспечения практико-ориентированности медицинского образования [1]. Достижение целей профессионального образования, обеспечение условий для повышения 